\title{
Colostrum from cows immunized with a veterinary vaccine against bovine rotavirus displays enhanced in vitro anti-human rotavirus activity
}

\author{
Andrea Civra, ${ }^{1 *}$ Alessandra Altomare, ${ }^{2 *}$ Rachele Francese, ${ }^{1}$ Manuela Donalisio, ${ }^{1}$ Giancarlo Aldini, ${ }^{2} \dagger$ \\ and David Lembo ${ }^{1} \dagger$ \\ ${ }^{1}$ Department of Clinical and Biological Sciences, University of Turin, 10043 Orbassano, Italy \\ ${ }^{2}$ Department of Pharmaceutical Sciences, Università degli Studi di Milano, 20133 Milan, Italy
}

\begin{abstract}
Human rotaviruses represent a major cause of severe diarrheal disease in infants and young children. The limited impact of oral vaccines on global estimates of rotavirus mortality and the suboptimal use of oral rehydration justify the need for alternative prophylactic and therapeutic strategies, especially for immunocompromised hosts. The protective effects of colostrum - the first milk produced during the initial 24 to $48 \mathrm{~h}$ after parturition - are well documented in the literature. In particular, the ingestion of hyperimmune bovine colostrum has been proposed as an alternative preventive approach against human rotavirus gastroenteritis. Although the immunization of pregnant cows with human rotavirus boosts the release of specific immunoglobulin $\mathrm{G}$ in bovine colostrum, it raises regulatory and safety issues. In this study, we demonstrated that the conventional bovine rotavirus vaccine is sufficient to enhance the anti-human rotavirus protective efficacy of bovine colostrum, thus providing a conservative approach to produce hyperimmune bovine colostrum, making it exploitable as a functional food.

Key words: rotavirus, colostrum, cows, hyperimmune, immunoglobulins
\end{abstract}

\section{INTRODUCTION}

Viral gastroenteritis represents a significant economic and public health burden, causing high morbidity and mortality rates, mainly in the poorest countries (Das et al., 2014). Human rotaviruses (HRoV) are a major cause of severe diarrheal disease in infants and young children are the second most common cause of death in children less than 5 years old (Marcotte and Hammarström, 2016). Because no specific antiviral drug

\footnotetext{
Received November 20, 2018.

Accepted February 24, 2019.

*These authors contributed equally to this work.

†Corresponding authors: giancarlo.aldini@unimi.it and david. lembo@unito.it
}

is available, conventional treatment for $\mathrm{HRoV}$ acute gastroenteritis is largely symptomatic and involves fluid and electrolyte replacement and maintenance of nutrition. Despite the introduction of oral $\mathrm{HRoV}$ vaccines that have significantly reduced the incidence of the disease in developed countries (Payne et al., 2013), the impact of this active prophylaxis on global estimates of HRoV mortality has been limited (Tate et al., 2016). This is mainly due to inadequate immunization coverage in lower income countries, where the burden of diarrheal disease is higher and vaccines are mostly needed. In fact, oral vaccines are less immunogenic when given to infants in low-income countries compared with high-income countries for a number of reasons, including transplacental maternally acquired antibodies, breastfeeding, histo blood group antigens, malnutrition, microbiota dysbiosis, and environmental enteropathy. Moreover, the scarce availability of vaccines in these areas, along with their contraindications in immunodeficient patients (Babji and Kang, 2012; Binder et al., 2014; Gaspar et al., 2014; Glass et al., 2014), leave between one-third and one-half of children unprotected from severe $\mathrm{HRoV}$ disease (Babji and Kang, 2012). These hindrances, together with the suboptimal use of therapeutic oral rehydration solutions, justify the development of effective alternative prophylactic and therapeutic approaches to prevent and control HRoV gastroenteritis disease, especially for immunocompromised hosts.

Colostrum is the first milk produced by mammary glands during the initial 24 to $48 \mathrm{~h}$ after parturition (Tokuyama et al., 1990; Stelwagen et al., 2009), and it represents a unique source of highly concentrated nutritional components (Macy, 1949) and growth factors (Pakkanen and Aalto, 1997) for the gastrointestinal development of mammalian newborns.

More importantly, colostrum provides neonates with essential passive immunity against infectious diseases (Ogra and Ogra, 1978; Morris et al., 1980; Majumdar and Ghose, 1982; Stephan et al., 1990; Tokuyama et al., 1990; Ebina et al., 1992; Cohen, 2006; Stelwagen 
et al., 2009). In particular, bovine colostrum (BC) has evolved into a highly effective host defense mechanism (Rainard and Riollet, 2006). In ruminants, no transplacental exchange of immune factors occurs in utero; therefore, colostrum and, to a lesser extent, mature milk provide protection through a high immunoglobulin content, without which the newborn would not survive (Larson et al., 1980). The immunoglobulins present in $\mathrm{BC}$ are $\operatorname{IgG}_{1}, \operatorname{IgG}_{2}, \operatorname{Ig} \mathrm{A}$, and $\operatorname{IgM}$ (Ogra and Ogra, 1978). The abundance of different immunoglobulin classes in colostrum and milk varies among species, with IgA being predominant in human mammary secretions. In contrast, in $\mathrm{BC}, \mathrm{IgG}_{1}$ is the most represented (Barrington et al., 1997), whereas IgA and IgM are present at much lower concentrations. The BC immunoglobulins, in conjunction with the ability of the ruminant neonatal gut to allow unrestricted passage of the large immunoglobulin molecules, provide the young animal with passive immunization (Bush and Staley, 1980; Moore et al., 2005).

Although the effect of colostrum is species-specific, a growing body of literature has documented the protective effect of $\mathrm{BC}$ against several viral infections in humans (Bojsen et al., 2007; Ng et al., 2010; Benson et al., 2012; Inagaki et al., 2014; El-Fakharany et al., 2017).

In particular, vaccination of cows against specific human pathogens results in polyclonal pathogen-specific antibodies in BC. The antibodies purified from this hyperimmune BC (HBC) have been exploited for the treatment of a variety of gastrointestinal infections caused by pathogenic bacteria (Playford et al., 2000; Kelly, 2003; Hammarström and Weiner, 2008; Struff and Sprotte, 2008) or viruses (Korhonen et al., 2000; Mehra, 2006; Inagaki et al., 2010, 2013; Ng et al., 2010; Byakwaga et al., 2011; Kramski et al., 2012a,b), indicating that $\mathrm{HBC}$ could be an alternative source for low-cost virus-specific antibodies. This evidence, together with the high content of antimicrobial peptides and proteins (e.g., lactoferrin, lactoperoxidase, and lysozyme) that can stimulate innate antiviral pathways and adaptive immune responses (Thapa, 2005; Smolenski et al., 2007; Stelwagen et al., 2009), suggests that $\mathrm{BC}$ could be exploited as a functional food to protect against viral infections.

Consistently, ingestion of $\mathrm{HBC}$ has been proposed as an alternative prophylactic approach against $\mathrm{HRoV}$ gastroenteritis (Ebina et al., 1992; Sarker et al., 1998). To date, HBC containing HRoV-specific, neutralizing IgG has been produced by immunizing pregnant cows with $\mathrm{HRoV}$ and harvesting colostrum after delivery. However, the additional costs and regulatory and safety issues arising from the use of an $\mathrm{HRoV}$ vaccine make it impossible to generate $\mathrm{HBC}$ on a large scale.
The alternative use of $\mathrm{BC}$ from nonimmunized cows (NHBC) may bypass these limits but, as expected, the literature has shown that NHBC has significantly lower anti-HRoV efficacy (Inagaki et al., 2010). In this study, we present proof-of-concept data showing a protective effect of HBC from cows vaccinated with a conventional bovine rotavirus strain (BRoV) against different HRoV genotypes.

\section{MATERIALS AND METHODS}

\section{Chemicals}

Laemmli buffer, molecular mass standards, and electrophoresis apparatus for one-dimensional electrophoresis were supplied by BioRad Laboratories Inc. (Hercules, CA). $\beta$-Mercaptoethanol, dithiothreitol, acetonitrile, SDS, iodoacetamide, formic acid, and all other chemicals used in the experimental work were products of pure analytical grade and purchased from SigmaAldrich Corp. (St. Louis, MO). Water and acetonitrile (Optima LC/MS grade) for liquid chromatography/MS analyses were purchased from Fisher Scientific (Loughborough, UK).

\section{Bovine Colostrum Collection}

Fresh $\mathrm{BC}$ and $\mathrm{HBC}$ samples were supplied by Advances in Medicine (AIM, Bologna, Italy). According to the supplier, colostrum was collected from both unvaccinated and vaccinated pregnant dairy Holstein cows. Three cows were immunized by subcutaneous inoculation of the inactivated trivalent vaccine Trivacton 6 (Merial Italia SpA, Milan, Italy) to maintain a maximum rate of antibodies in colostral secretions against Escherichia coli, rotavirus, and coronavirus, which are implied in the development of neonatal diarrhea. Vaccination was performed with a 2-injection schedule, administered $2 \mathrm{mo}$ and $4 \mathrm{wk}$ before parturition, respectively. Colostrum from the 3 vaccinated cows was collected until $5 \mathrm{~h}$ after birth, pooled, and immediately frozen at $-20^{\circ} \mathrm{C}$. Concentrations of IgG in whole colostrum samples was $50 \mathrm{mg} / \mathrm{mL}$ (protein content: 12\%), as assessed by previously described methods (Sacerdote et al., 2013).

After a suitable dilution with demineralized water (1 volume), the suspension was introduced into a sterile beaker (controlled continuous stirring) and heated at $\sim 38^{\circ} \mathrm{C}$ for about $1 \mathrm{~h}$. The suspension was skimmed by removing the fatty layer using a sterile spatula, and caseins were removed by adjusting the $\mathrm{pH}$ to their isoelectric point $(\mathrm{pH} 4.6$ with $1 \mathrm{M} \mathrm{HCl})$. After $1 \mathrm{~h}$, the product was centrifuged at $2,500 \times g$ for $45 \mathrm{~min}$ at $25^{\circ} \mathrm{C}$ to ensure removal of all caseins. Low-molecular- 
weight components, including salts and lactose, were then removed by using hollow-fiber cross-flow filtration cartridges (GE Healthcare Bio-Sciences Corp., Westborough, MA.) with a nominal molecular weight cutoff of 4000 coupled to a tangential flow filtration system equipped with a peristaltic pump essential to keep the flow recirculation continuous (Kross Flo-Tangential flow Filtration System Research III, Spectrum Laboratories Inc., Rancho Dominguez, CA). The $\mathrm{pH}$ of the retentate was then adjusted to $7.0 \pm 0.2$ with $1 \mathrm{M} \mathrm{NaOH}$, the neutralized sample was centrifuged at $12,000 \times g$ for $40 \mathrm{~min}$ at $25^{\circ} \mathrm{C}$, and the supernatant was retained. The next steps consisted of clarification through 0.45 - and $0.22-\mu \mathrm{m}$ filters followed by lyophilization.

\section{Bovine IgG Purification}

Affinity Chromatography. Immunoglobulin G was purified by affinity chromatography, using protein $\mathrm{G}$ from streptococci as the stationary phase, immobilized in a preparative chromatographic column. In detail, the affinity column was prepared by packing $400 \mathrm{~mL}$ of Protein G Sepharose 4 Fast Flow resin (GE Healthcare, Chicago, IL) in a HiScale 50 column support (GE Healthcare), which was connected to a fast protein liquid chromatography (FPLC) system (ÄKTAprime plus, GE Healthcare). Chromatographic purification started by eluting the column with 5 volumes $(5 \times$ chromatographic bed volume) of buffer A (binding buffer: $20 \mathrm{~m} M$ sodium phosphate, $\mathrm{pH} 7$ ), and then the sample was loaded at a flow rate of $20 \mathrm{~mL} /$ min. The eluate was monitored by a UV detector at 280 $\mathrm{nm}$, a conductivity meter $(0.001-999.9 \mathrm{mS} / \mathrm{cm})$, and a $\mathrm{pH}$ meter; all fractions characterized by significant UV absorption were automatically collected (IgG-depleted fractions). The subsequent step consisted of recovering the IgG fractions (IgG-enriched fractions) by eluting the column with $100 \%$ elution buffer ( $1 M$ glycine hydrochloride $\mathrm{pH} 2.5$ ). Column regeneration was carried out by eluting 5 volumes $(5 \times$ chromatographic bed volume) of $20 \%$ ethanol.

Tangential Flow Filtration. The IgG-enriched and IgG-depleted fractions obtained above were mixed and subjected to concentration and desalting using hollowfiber cross-flow filtration cartridges with a nominal molecular weight cutoff of 3000 and a surface area of $650 \mathrm{~cm}^{2}$ (GE Healthcare) coupled to a tangential flow filtration system equipped with a peristaltic pump essential to keep the flow recirculation continuous (Kross Flo- Tangential flow Filtration System Research III). The IgG-enriched and IgG-depleted fractions were concentrated 20 to 30 times, dialyzed with 5 volumes of water, filtered through $0.22-\mu \mathrm{m}$ membranes in sterile conditions, and finally lyophilized.

\section{Separation of Proteins on Polyacrylamide Gel}

One-dimensional (SDS-PAGE) protein separation was performed under reducing conditions; $10-\mu \mathrm{L}$ aliquots of samples containing 20 to $25 \mu \mathrm{g}$ of protein were mixed with $10 \mu \mathrm{L}$ of Laemmli sample buffer containing $50 \mathrm{~m} M$ dithiothreitol and heated at $95^{\circ} \mathrm{C}$ for $5 \mathrm{~min}$. Samples and a standard protein mixture (Precision Plus Protein Standards, BioRad Laboratories Inc.) were loaded on precast gels (Any KD Mini Protean TGX, BioRad Laboratories Inc.) and then placed in the electrophoresis cell (Mini-Protean Tetra) and run at $200 \mathrm{~V}$ (constant) for 30 to $40 \mathrm{~min}$. Staining was carried out using Coomassie blue stain (Biosafe G250 Stain, BioRad Laboratories Inc.) and the images acquired by using the BioRad GS800 densitometer and analyzed using the software Quantity One 1-D (BioRad Laboratories Inc.).

\section{IgG and IgM Analysis by Size Exclusion Chromatography}

The IgG contents of the IgG-enriched and IgGdepleted fractions were then determined by size exclusion chromatography (SEC) according to the method reported by Altomare et al. (2016b); SEC was performed on a Thermo Finnigan Surveyor HPLC system (ThermoFinnigan Italia, Milan, Italy) equipped with a variable wavelength detector and an auto-sampler, controlled by Xcalibur software (version 2.0.7 Thermo Fisher Scientific, Rodano, Italy). The SEC separation was performed on a 4.6- $\times 300-\mathrm{mm}$ Phenomenex Yarra 3u SEC-3000 column (Phenomenex Inc., Torrance, $\mathrm{CA}$ ), with a $4 \times 3 \mathrm{~mm}$ GFC4000 pre-column (Phenomenex Inc.), by running an isocratic flow of mobile phase containing $0.1 M$ sodium phosphate bibasic, $0.025 \%$ sodium azide, $\mathrm{pH} 6.8$, at a constant flow rate of $0.5 \mathrm{~mL} / \mathrm{min}$. The autosampler temperature was set at $8^{\circ} \mathrm{C}$ and UV detection was conducted at a wavelength of $280 \mathrm{~nm}$, typical wavelength for protein detection. The dipeptide tyrosine-histidine (TH) was chosen as internal standard, because it marks the racing front, being the smallest analyte. All samples were previously spiked with a small amount of $\mathrm{TH}(10 \mu \mathrm{L})$ in order to obtain a final concentration of $0.3 \mathrm{~m} M$.

\section{Cell Lines and Viruses}

African green monkey kidney epithelial cells (MA104) and human epithelial adenocarcinoma HeLa cells (ATCC CCL-2) were propagated in Dulbecco's modified Eagle's medium (DMEM; Gibco-BRL, Gaithersburg, MD) supplemented with heat-inactivated $10 \%$ fetal bovine serum (Gibco-BRL) and 1\% antibiotic-antimycotic 
solution (Zell Shield, Minerva Biolabs GmbH, Berlin, Germany), at $37^{\circ} \mathrm{C}$ in an atmosphere of $5 \%$ of $\mathrm{CO}_{2}$. African green monkey kidney cells (Vero cells; ATCC CCL-81) were grown as monolayers in Eagle's minimal essential medium (Gibco/BRL) supplemented with $10 \%$ fetal bovine serum and 1\% antibiotic-antimycotic solution. The HRoV strains Wa (ATCC VR-2018), HRV408 (ATCC VR-2273), and HRV248 (ATCC VR-2274) and the BRoV strain NCDV (ATCC VR-1290) were activated with $5 \mu \mathrm{g} / \mathrm{mL}$ porcine pancreatic trypsin type IX (Sigma-Aldrich Co.) for $30 \mathrm{~min}$ at $37^{\circ} \mathrm{C}$ and propagated in MA104 cells using DMEM containing $0.5 \mu \mathrm{g}$ of trypsin per $\mathrm{mL}$ as described previously (Civra et al., 2015). Viral titers are expressed as focus-forming units (FFU) per milliliter. A serologic characterization of the rotaviruses exploited in this study is provided in Table 1. Human rhinovirus (HRhV) 1A (ATCC VR-1559) was propagated in HeLa cells at $34^{\circ} \mathrm{C}$ in a humidified $5 \% \mathrm{CO}_{2}$ incubator. Clinical isolates of human herpes simplex virus type 1 (HSV1) and type 2 (HSV2) were provided by M. Pistello (University of Pisa, Italy). Human cytomegalovirus (HCMV) strain Towne was provided by W. Brune (Heinrich Pette Institut, Hamburg, Germany). Vesicular stomatitis virus (VSV; ATCC VR-1238), HCMV, HSV1, and HSV2 were propagated in Vero cells at $37^{\circ} \mathrm{C}$ in a humidified $5 \% \mathrm{CO}_{2}$ incubator. When the full cytopathic effect developed, cells and supernatants were harvested, pooled, frozen and thawed 3 times, clarified, and aliquoted. Viruses were stored at $-70^{\circ} \mathrm{C}$. Viral titers were determined by the standard plaque method as described previously (Civra et al., 2014; Cagno et al., 2017), and expressed as plaqueforming units per milliliter $(\mathrm{PFU} / \mathrm{mL})$.

\section{Focus Reduction Assay}

Antiviral activity of NHBC, HBC, or IgG against HRoV Wa, HRV408, HRV248, and NCDV was determined by focus reduction assay or plaque reduction assay. Assays of inhibition of rotavirus infectivity were carried out with confluent MA104 cell monolayers plated in 96-well trays, as described elsewhere (Civra et al., 2014). Cells were treated for $2 \mathrm{~h}$ at $37^{\circ} \mathrm{C}$ with serial dilutions of colostrum, at protein concentrations ranging from 0.02 to $3,340 \mu \mathrm{g}$ of protein $/ \mathrm{mL}$ in serum-free medium before virus addition. Infection with $\mathrm{HRoV}$ was performed at a multiplicity of infection (MOI) of $0.02 \mathrm{FFU} / \mathrm{mL}$ for $1 \mathrm{~h}$ at $37^{\circ} \mathrm{C}$, in presence of the colostrums. Infected cells were washed with serum-free medium, fresh methanol extract was added, and cells were incubated in this medium at $37^{\circ} \mathrm{C}$ in a humidified incubator in $5 \%$ (vol/vol) $\mathrm{CO}_{2}$ in $95 \%$ (vol/vol) air. After $16 \mathrm{~h}$ of incubation, infected cells were fixed with
Table 1. Rotavirus strains used in this study ${ }^{1}$

\begin{tabular}{lll}
\hline Strain & Origin & Serotype $^{2}$ \\
\hline Wa & Human & G1[P8] \\
HRV408 & Human & Natural reassortant G3[P?] \\
HRV248 & Human & Natural reassortant G4[P4] \\
NCDV & Bovine & G6[P1]
\end{tabular}

${ }^{1}$ The characteristics of the rotavirus strains are from Parrón et al. (2018) and Rahman et al. (2012).

${ }^{2}[\mathrm{P} ?]=\mathrm{P}$ genotype unknown .

cold acetone-methanol (50:50), and viral titers determined by indirect immunostaining by using a mouse monoclonal antibody directed to human rotavirus VP6 (0036; Covalab, Villeurbanne, France), and the secondary antibody peroxidase-conjugated AffiniPure $\mathrm{F}\left(\mathrm{ab}^{\prime}\right)_{2}$ Fragment Goat Anti-Mouse IgG $\left(\mathrm{H}^{+} \mathrm{L}\right)$ (Jackson ImmunoResearch Laboratories Inc., West Grove, PA).

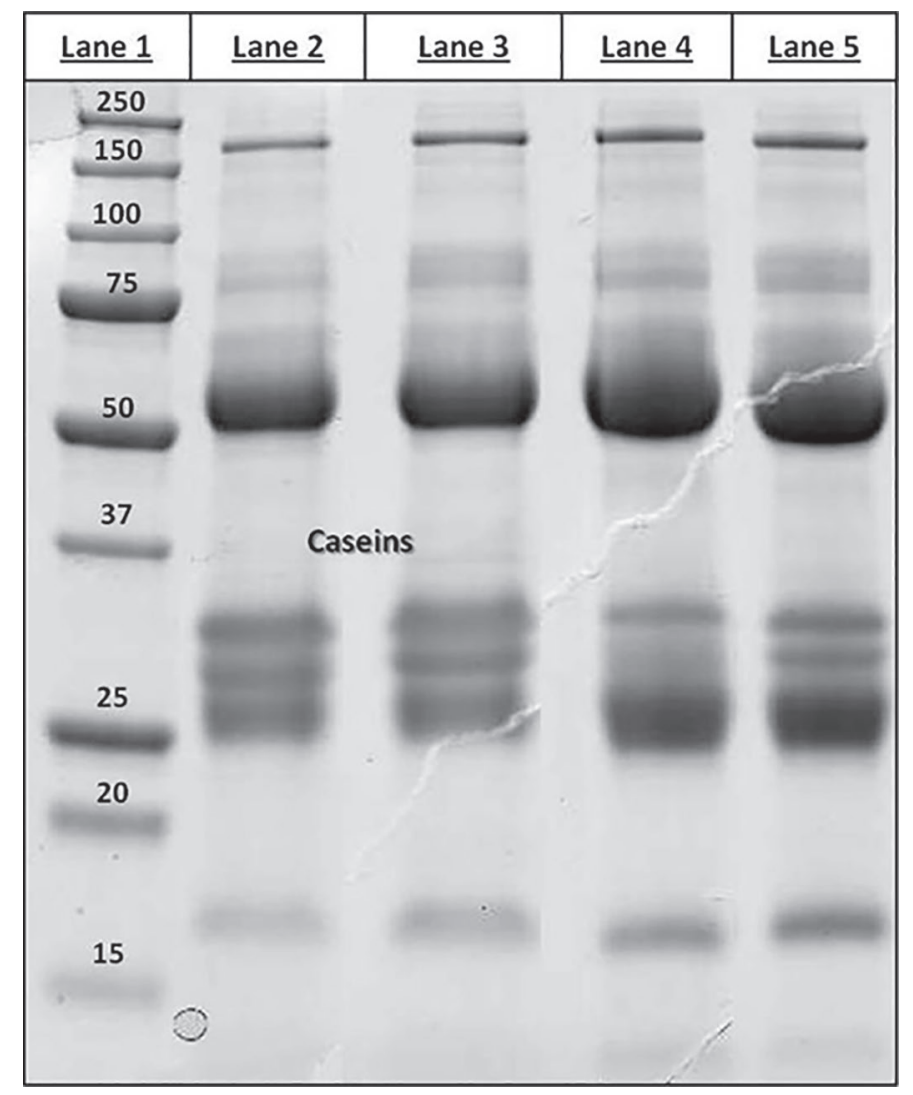

Figure 1. Sodium dodecyl sulfate-PAGE profiling of colostrum proteins. Lane $1=$ Precision Plus Protein Standard (BioRad Laboratories, Hercules, CA); lane $2=$ untreated bovine colostrum; lane 3 = untreated hyperimmune bovine colostrum; lane $4=$ bovine colostrum defatted, casein-depleted, dialyzed, and filtered; lane $5=$ hyperimmune bovine colostrum defatted, casein-depleted, dialyzed, and filtered. 


\section{Plaque Reduction Assay}

For the plaque reduction assay, HeLa or Vero cells were first seeded (at $8 \times 10^{4}$ cells/well) in 24-well plates. Twenty-four hours later, HBC, NHBC, or IgG was serially diluted in medium (from 0.02 to $3,340 \mu \mathrm{g}$ of protein $/ \mathrm{mL}$ ) and added to cell monolayers. After $2 \mathrm{~h}$ of incubation $\left(37^{\circ} \mathrm{C}, 5 \% \mathrm{CO}_{2}\right)$, medium was removed and infection was performed with $200 \mu \mathrm{L} /$ well of HRhV 1A, VSV, HSV-1, HSV-2, or HCMV at an MOI of $0.0002 \mathrm{PFU} / \mathrm{mL}$ in presence of colostrums. The infected cells were incubated at $34^{\circ} \mathrm{C}$ for $\mathrm{HRhV}$ infections or $37^{\circ} \mathrm{C}$ for the other viruses for $1 \mathrm{~h}$, washed with medium, and overlaid with a 1:1 combination of $1.6 \%$ SeaPlaque Agarose and $2 \times$ DMEM containing the colostrums. Control wells (100\% of infection) were prepared by treating cells with equal volumes of culture medium. The plates were incubated at $34^{\circ} \mathrm{C}$ or $37^{\circ} \mathrm{C}$ for $3 \mathrm{~d}$. After incubation, the plates were fixed with $7.5 \%$ formaldehyde (Fluka, Bucharest, Romania) and stained with crystal violet (Sigma-Aldrich Co.). The number of plaques formed was counted.

\section{Rotavirus Neutralization Assay}

Immunoglobulin G precipitated with ammonium sulfate (AS) was added at a $90 \%$ effective concentration $\left(\mathbf{E C}_{\mathbf{9 0}}\right)$ to $2 \times 10^{5} \mathrm{FFU} / \mathrm{mL}$ of trypsin-activated RoV suspension and mixed in a total volume of $200 \mu \mathrm{L}$. Untreated or negative controls were performed with an equal volume of culture medium or AS supernatant.

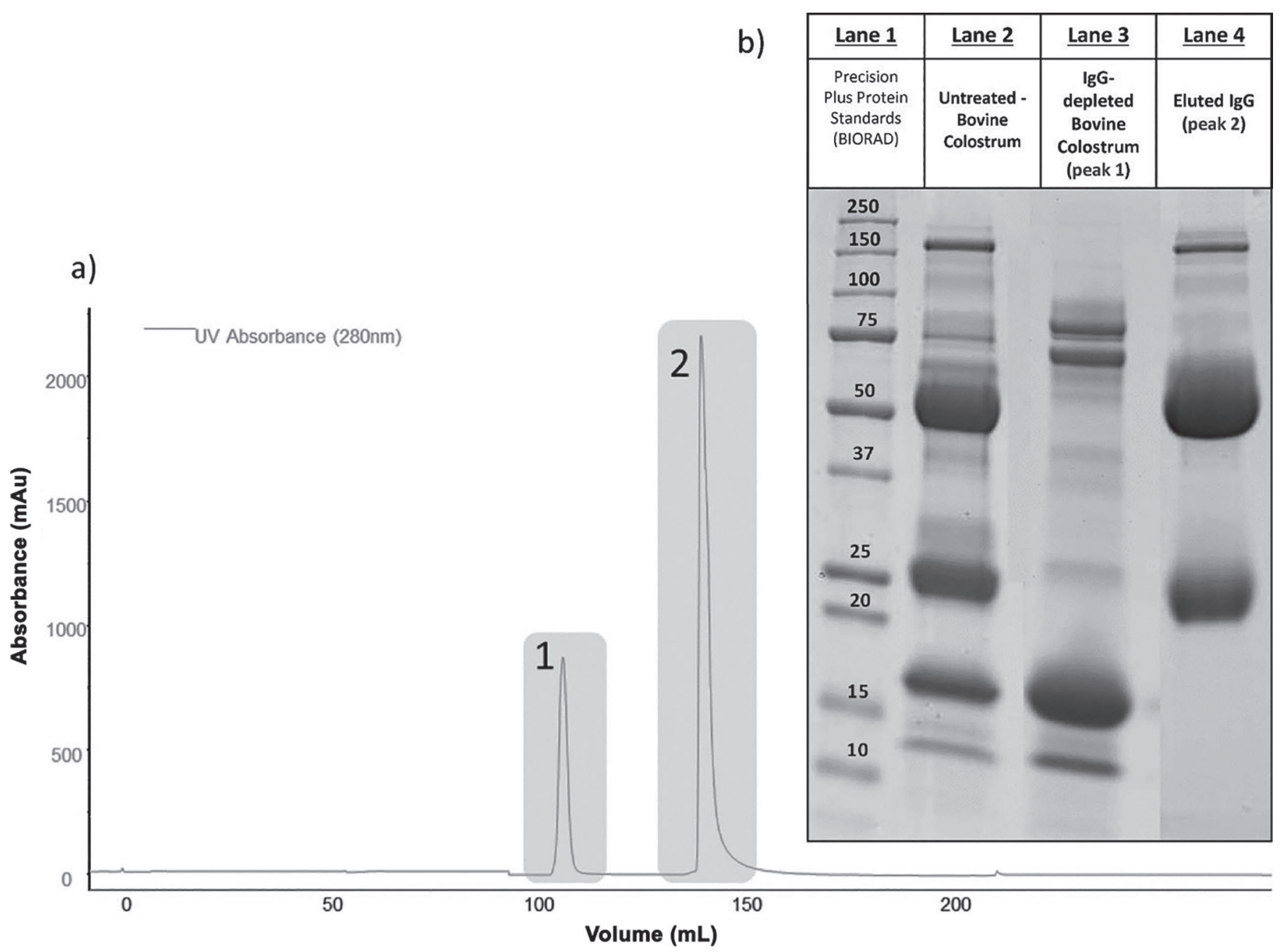

Figure 2. Purification of IgG by affinity chromatography. (a) Fast protein liquid chromatography-UV chromatogram of the untreated-bovine colostrum (casein-depleted and defatted colostrum) obtained by using protein $\mathrm{G}$ as affinity stationary phase; peaks 1 and 2 represent, respectively, the IgG-depleted and IgG-enriched fractions as demonstrated by the SDS-PAGE patterns. (b) Gel electrophoretic pattern of peaks 1 (lane 3 ) and 2 (lane 4) compared with the untreated bovine colostrum pattern, run under reducing conditions. The characteristic bands at 25 and 50 Da are evident in peak 2 and negligible in peak 1 . BIORAD = BioRad Laboratories (Hercules, CA). 
The virus-compound mixtures were incubated for $1 \mathrm{~h}$ at $37^{\circ} \mathrm{C}$, serially diluted to the noninhibitory concentration of test IgG, and the residual viral infectivity was determined as previously described (Civra et al., 2014).

\section{Rotavirus-Cell Binding Assay}

Rotavirus-cell binding assays were performed as described previously (Civra et al., 2015). Trypsin-activated RoV strains Wa, HRV248, HRV408, and NCDV were treated as described for the neutralization assays. After $1 \mathrm{~h}$, cells were washed with fresh medium and cooled on ice. The RoV were then cooled to $4^{\circ} \mathrm{C}$ and allowed to attach to cells for $1 \mathrm{~h}(\mathrm{MOI}=3 \mathrm{FFU} /$ cell $)$ at $4^{\circ} \mathrm{C}$. After a wash with cold DMEM, cells were subjected to 2 rounds of freeze/thawing and then incubated at $37^{\circ} \mathrm{C}$ for $30 \mathrm{~min}$ with $10 \mu \mathrm{g} / \mathrm{mL}$ porcine trypsin to release bound virus. The lysates were then clarified by lowspeed centrifugation for $10 \mathrm{~min}$, and cell-bound virus titers were determined by indirect immunostaining as above.

\section{Cell Viability Assay}

Cells were seeded at a density of $5 \times 10^{3} /$ well in 96 well plates and treated the next day with HBC, NHBC, $\mathrm{IgG}$, or AS supernatant at concentrations ranging from 0.02 to $7,140 \mu \mathrm{g} / \mathrm{mL}$ to generate dose-response curves. Control samples ( $100 \%$ of viability) were prepared by treating cells with culture medium. After 24 or $72 \mathrm{~h}$ of incubation, cell viability was determined using a CellTiter 96 Proliferation Assay Kit (Promega, Madison, WI), following the manufacturer's instructions. Absorbances were measured using a Microplate Reader

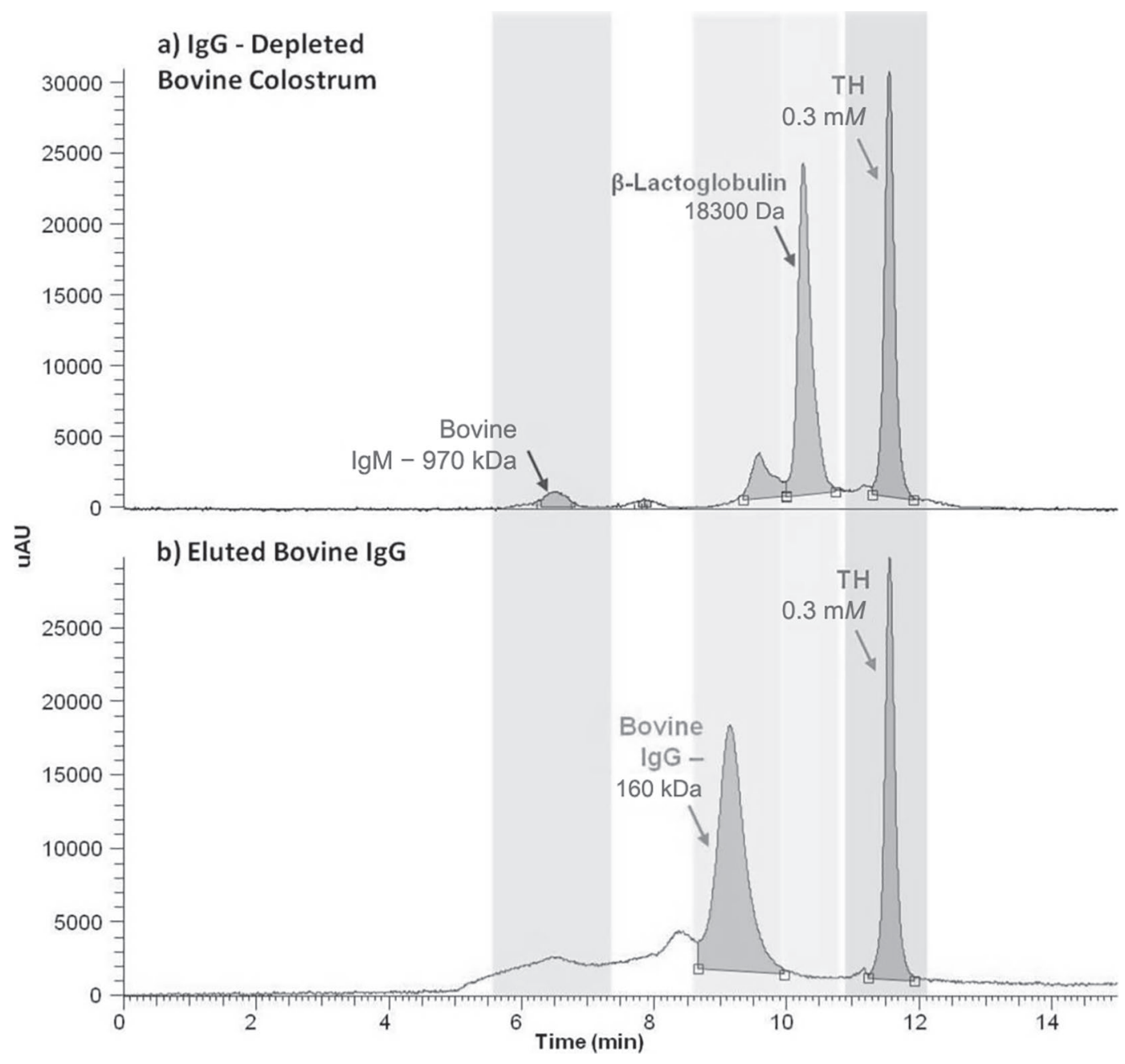

Figure 3. Analysis of IgG by size exclusion chromatography (SEC)-UV; (a) shows the SEC-UV chromatogram of the IgG-depleted bovine colostrum sample, using the dipeptide tyrosine-histidine (TH) as internal standard; (b) shows the SEC-UV chromatogram of IgG purified fraction from bovine colostrum. 
(model 680, BioRad Laboratories) at $490 \mathrm{~nm}$. Viability of treated cells was expressed as a percentage relative to cells incubated with culture medium.

\section{Statistical Assessments}

Blockades of viral infectivity were expressed as mean percent \pm standard deviation (SD). Where possible, antiviral effective concentration $\left(\mathbf{E C}_{50}\right)$ values were calculated by regression analysis using the dose-response curves generated from the experimental data, using Prism 4 (GraphPad Software, San Diego, CA). The $50 \%$ cytotoxic concentration $\left(\mathbf{C C}_{50}\right)$ was determined using logarithmic viability curves. Where possible, a selectivity index $(\mathbf{S I})$ was calculated by dividing $\mathrm{CC}_{50}$ by $\mathrm{EC}_{50}$. One-way ANOVA followed by Bonferroni test was used to assess the statistical significance of the differences between treated and untreated samples. The $\mathrm{EC}_{50}$ values were compared using the sum-of-squares $F$ test. Significance was set at the $95 \%$ level.

\section{RESULTS}

\section{One-Dimensional Gel Electrophoresis}

Figure 1 displays the SDS-PAGE profile of colostrum proteins (under reducing conditions) relative to the following samples: colostrum from nonimmunized (lane 2) and immunized (lane 3) cows and the corresponding defatted, casein-depleted, dialyzed, filtered samples (lanes 4 and 5). As expected, all protein profiles showed 2 intense bands at approximately 50 and $25 \mathrm{kDa}$, representing the heavy and light IgG chains, respectively. The other bands represent the classical set of high-abundance species normally found in any milk of animal origin (although in colostrum, IgG alone represent $\sim 80 \%$ of the total protein mass), including

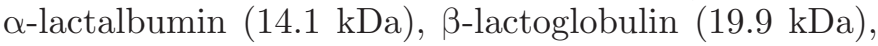
serum transferrin $(77.7 \mathrm{kDa})$, and $\alpha 2$-macroglobulin $(167.5 \mathrm{kDa})$. As expected, the protein patterns relative to colostrum samples differed in respect to the corresponding defatted, casein-depleted, dialyzed, filtered samples by a significant reduction in the bands attributable to the caseins (lanes 2 and 3, Figure 1).

\section{Bovine IgG Purification by Affinity Chromatography}

Purification of $\mathrm{Ig} G$ from colostrum collected from nonimmunized and immunized cows was achieved by using a preparative affinity chromatography system based on protein $\mathrm{G}$ from streptococci, which is highly selective against bovine IgG.

The affinity chromatogram trace, recorded at 280 $\mathrm{nm}$, displayed 2 peaks: the first (not retained) corresponded to the non-immunoglobulin protein fraction, and the second to the IgG fraction (Figure 2a), the

Table 2. Antiviral activities ${ }^{1}$ of bovine colostrums (BC)

\begin{tabular}{|c|c|c|c|c|}
\hline $\begin{array}{l}\mathrm{BC} \text { and virus } \\
\text { (strain) }\end{array}$ & $\begin{array}{c}\mathrm{EC}_{50}(\mu \mathrm{g} / \mathrm{mL}) \\
(95 \% \mathrm{CI})\end{array}$ & $\begin{array}{c}\mathrm{EC}_{90}(\mu \mathrm{g} / \mathrm{mL}) \\
(95 \% \mathrm{CI})\end{array}$ & $\begin{array}{c}\mathrm{CC}_{50} \\
(\mu \mathrm{g} / \mathrm{mL})\end{array}$ & SI \\
\hline \multicolumn{5}{|l|}{ Nonimmune BC } \\
\hline HSV-1 & $\mathrm{NA}^{3}$ & NA & $>6,680$ & - \\
\hline HSV-2 & NA & NA & $>6,680$ & - \\
\hline HCMV & NA & NA & $>6,680$ & - \\
\hline $\mathrm{HRhV}$ & NA & NA & $>6,680$ & - \\
\hline HRoV (Wa) & $2.3(1.6-3.5)$ & $16.3(6.8-39.1)$ & $>6,680$ & $>2,855$ \\
\hline HRoV (HRV408) & $12.6(8.6-18.7)$ & $90(38-215)$ & $>6,680$ & $>529$ \\
\hline HRoV (HRV248) & $4.2(2.4-7.3)$ & $134(39-454)$ & $>6.680$ & $>1.591$ \\
\hline BRoV (NCDV) & $61(44-86)$ & $143(97-211)$ & $>6,680$ & $>109$ \\
\hline VSV & $64(55-75)$ & $343(252-467)$ & $>6,680$ & $>104$ \\
\hline \multicolumn{5}{|l|}{ Hyperimmune BC } \\
\hline HSV-1 & NA & NA & $>7,140$ & - \\
\hline HSV-2 & $6,018(2,560-14,110)$ & NA & $>7,140$ & $>1.18$ \\
\hline HCMV & NA & $\mathrm{NA}$ & $>7,140$ & - \\
\hline HRhV & NA & NA & $>7.140$ & - \\
\hline HRoV (Wa) & $0.3(0.3-0.5)$ & $4.5(2.4-8.5)$ & $>7,140$ & $>21,000$ \\
\hline HRoV (HRV408) & $2.1(1.7-2.6)$ & $7.6(4.7-12.5)$ & $>7,140$ & $>3,449$ \\
\hline HRoV (HRV248) & $1.6(1.2-2.8)$ & $8.1(5.6-11.6)$ & $>7,140$ & $>4,519$ \\
\hline BRoV (NCDV) & $5.5(3.7-8.2)$ & $51(21-122)$ & $>7,140$ & $>1,301$ \\
\hline VSV & $89(60-132)$ & $489(200-1198)$ & $>7,140$ & $>80$ \\
\hline
\end{tabular}

${ }^{1} \mathrm{EC}_{50}=$ half-maximal effective concentration; $\mathrm{EC}_{90}=90 \%$ effective concentration; $\mathrm{CC}_{50}=$ half-maximal cytotoxic concentration; $\mathrm{SI}=$ selectivity index $\left(\mathrm{CC}_{50} / \mathrm{EC}_{50}\right)$.

${ }^{22} \mathrm{HSV}-1$ = herpes simplex type 1 ; HSV-2 = herpes simplex type 2; HCMV = human cytomegalovirus; HRhV $=$ human rhinovirus; $\mathrm{HRoV}=$ human rotavirus; $\mathrm{BRoV}=$ bovine rotavirus; $\mathrm{VSV}=$ vesicular stomatitis virus.

${ }^{3}$ Not assessable. 
peak of which accounted for $80 \%$. The electrophoretic patterns obtained for the 2 collected fractions (Figure $2 \mathrm{~b}$ ) indicated good depletion of immunoglobulins, whose characteristic bands at 160,50 , and $25 \mathrm{kDa}$ were very weak in the aliquot eluted within the first peak and much more intense in the fraction of the second peak, corresponding to the immunoglobulins.

\section{SEC-UV for IgG Analysis}

A SEC-UV method was optimized to achieve reproducible separation of the most abundant analytes in bovine colostrum; the method was then applied to

a
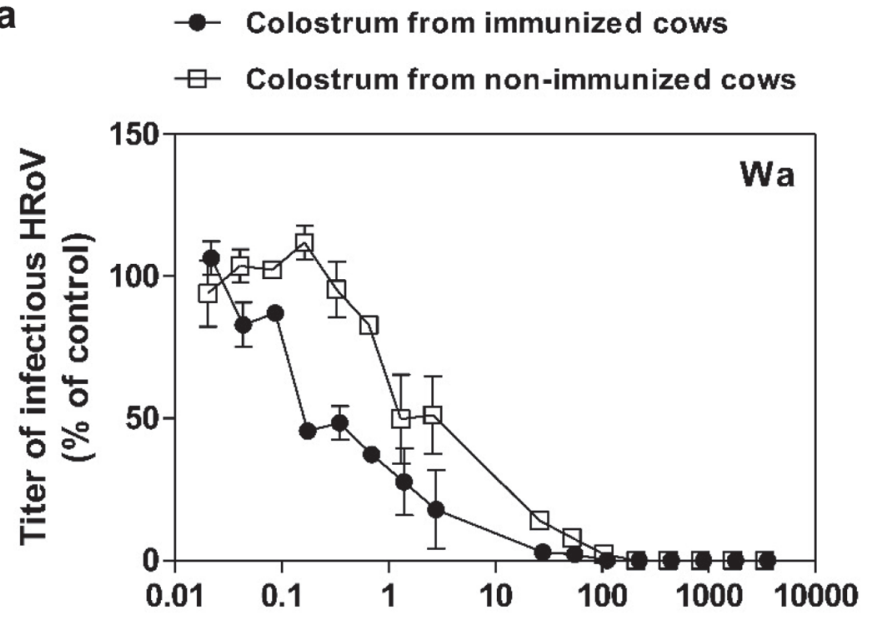

b

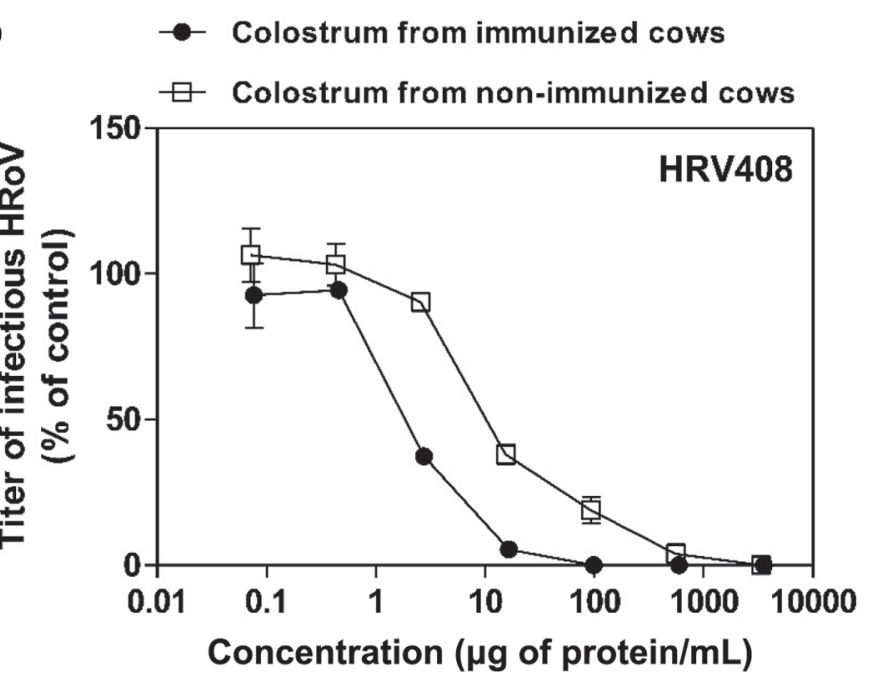

verify the purity of the fractions obtained: the nonimmunoglobulin protein fraction and the IgG eluted fraction.

Figure 3 represents typical chromatograms recorded by setting the UV detector at $280 \mathrm{~nm}$ and relative to the IgG-depleted (Figure 3a) and IgG-enriched (Figure $3 \mathrm{~b})$ fractions, each spiked with the internal standard $\mathrm{TH}(0.3 \mathrm{mM})$. The typical retention times for IgG and the dipeptide TH were 9.15 and $11.57 \mathrm{~min}$, respectively. The peak relative to IgG was evident only in the IgGenriched fraction and absent in the IgG-depleted fraction, which was characterized by other peaks such as representing IgM and $\beta$-lactoglobulin
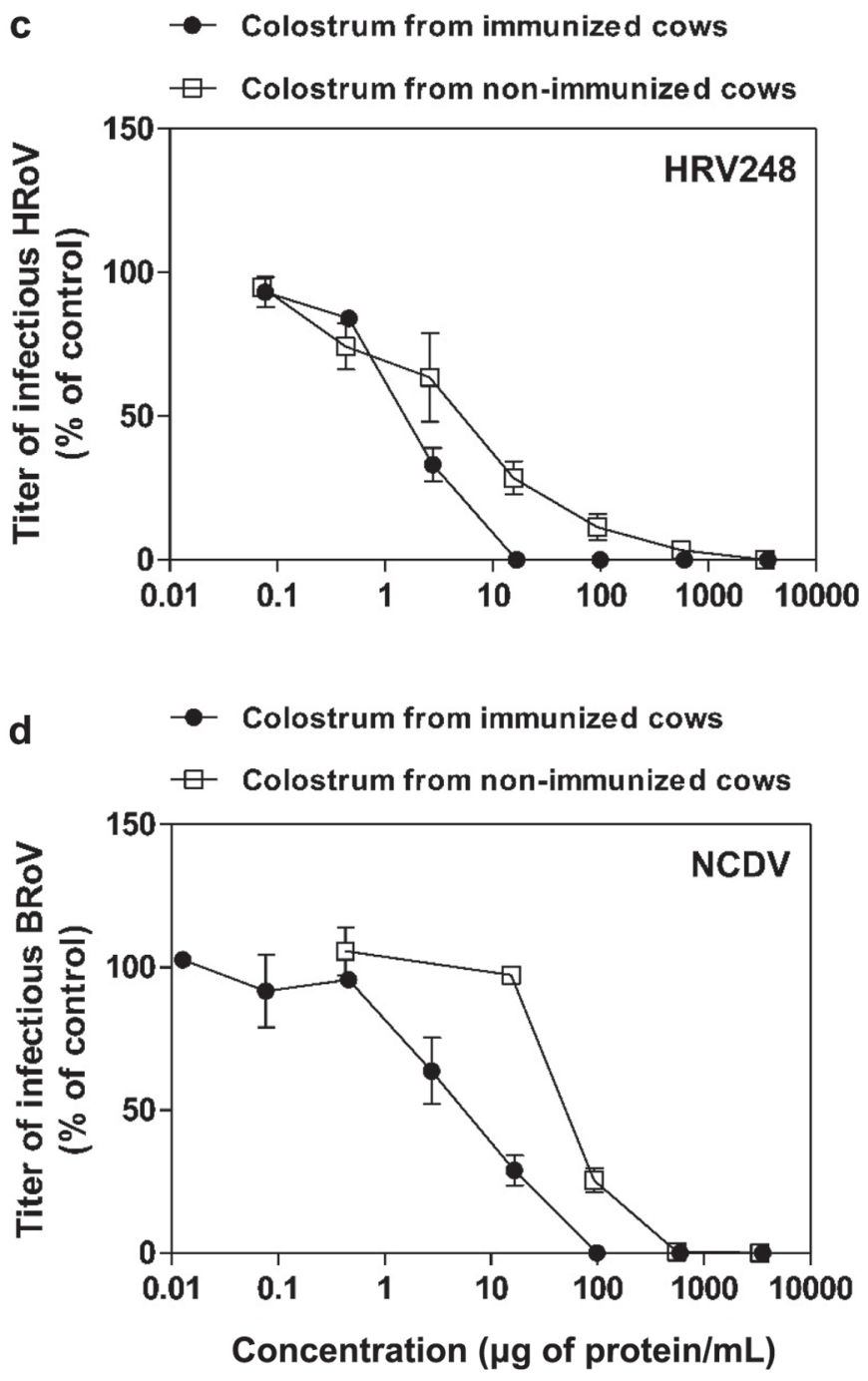

Figure 4. Antiviral activity of colostrum from immunized cows (hyperimmune bovine colostrum, HBC) and colostrum from nonimmunized cows (NHBC) against human rotavirus (HRoV) strains Wa (a), HRV408 (b), and HRV248 (c) and bovine rotavirus (BRoV) strain NCDV (d) on MA104 cells. Cells were treated for $2 \mathrm{~h}$ with increasing concentrations of colostrum and then infected in the presence of colostrum. Viral infections were detected as described in the Material and Methods. The percentage infection was calculated by comparing treated and untreated wells. The results are means and SEM for duplicates. 


\section{Antiviral Activity Assessment}

After their biochemical characterization, colostrums and IgG samples were tested for antiviral activity. The results summarized in Table 2 show that neither NHBC nor HBC had antiviral activity against human pathogens, including HSV-1, HCMV, or HRhV. Although HBC showed a weak antiviral activity against HSV-2, nevertheless it was not able to inhibit viral infectivity to $100 \%$. As expected, NHBC was effective against bovine pathogens such as $\mathrm{BRoV} \operatorname{NCDV}\left(\mathrm{EC}_{50}=61.5\right.$ $\mu \mathrm{g}$ of protein $/ \mathrm{mL})$ and $\mathrm{VSV}\left(\mathrm{EC}_{50}=64 \mu \mathrm{g}\right.$ of protein/ $\mathrm{mL}$; Table 2). Of note, NHBC had non-strain-restricted antiviral efficacy against the $\mathrm{HRoV}$ strains $\mathrm{Wa}\left(\mathrm{EC}_{50}\right.$ $=2.3 \mu \mathrm{g}$ of protein $/ \mathrm{mL})$, HRV248 $\left(\mathrm{EC}_{50}=4.2 \mu \mathrm{g}\right.$ of protein $/ \mathrm{mL})$, and HRV408 $\left(\mathrm{EC}_{50}=12.6 \mu \mathrm{g}\right.$ of protein/ $\mathrm{mL}$ ) with percentages of inhibition up to $100 \%$ (Figure 4). To test the hypothesis that colostrum from cows immunized with a veterinary anti-BRoV vaccine may exert a higher anti-HRoV activity than that from nonimmunized cows, we performed a second set of antiviral assays. As expected, HBC exerted significantly $(P<$ 0.0001; $F$ test) higher antiviral activity against BRoV $\operatorname{NCDV}\left(\mathrm{EC}_{50}=5.5 \mu \mathrm{g}\right.$ of protein $\left./ \mathrm{mL}\right)$, compared with colostrum of nonimmunized cows (Table 2). This result indicates that vaccination elicited an anti-BRoV immune response. Notably, HBC was also significantly $(0.0001<P<0.0005 ; F$ test $)$ more effective than NHBC against $\mathrm{Wa}\left(\mathrm{EC}_{50}=0.3 \mu \mathrm{g}\right.$ of protein $\left./ \mathrm{mL}\right)$, HRV $248\left(\mathrm{EC}_{50}=1.6 \mu \mathrm{g}\right.$ of protein $\left./ \mathrm{mL}\right)$, and HRV408 $\left(\mathrm{EC}_{50}=2.1 \mu \mathrm{g}\right.$ of protein $/ \mathrm{mL}$; Table 2$)$, suggesting a high titer of cross-reactive IgG in HBC. Therefore, we performed a third set of experiments to test the presence of anti-HRoV IgG in HBC-derived IgG. The results shown in Table 3 and Figure 5 demonstrate that these IgG inhibit the infectivity of BRoV strain NCDV $\left(\mathrm{EC}_{50}=6.2 \mu \mathrm{g}\right.$ of protein $\left./ \mathrm{mL}\right)$ but, more interestingly, also have strong antiviral activity against $\mathrm{HRoV}$ strains Wa $\left(\mathrm{EC}_{50}=1.9 \mu \mathrm{g}\right.$ of protein $\left./ \mathrm{mL}\right), \operatorname{HRV} 248\left(\mathrm{EC}_{50}=\right.$ $0.7 \mu \mathrm{g}$ of protein $/ \mathrm{mL})$, and HRV408 $\left(\mathrm{EC}_{50}=1.8 \mu \mathrm{g}\right.$ of protein $/ \mathrm{mL}$ ) with percentages of inhibition up to $100 \%$. As a negative control for IgG antiviral assays, we treated cells with equal volumes of IgG-depleted AS supernatant; results shown in Table 3 and Figure 5 show that the IgG-depleted AS supernatant did not have significant antiviral activity. Notably, treatment of the different cell lines with NHBC, HBC, and IgG did not affect cell viability, even at high concentrations, showing that the antiviral activity we observed was not caused by nonspecific cytotoxic effects.

Mechanism of action experiments show that these IgG neutralize virus infectivity by significantly $(0.0103$ $<P<0.0155$; ANOVA) inhibiting RoV-cell binding (Figure 6a,b,c). More importantly, the significant $(0.0005<P<0.0183 ;$ ANOVA $)$ neutralization of viral infectivity observed in virus inactivation assays (Figure $6 \mathrm{~d}, \mathrm{e}, \mathrm{f})$ was consistent with a neutralizing activity of virus-specific antibodies targeting RoV surface antigens, rather than cellular receptors.

\section{DISCUSSION}

The supportive properties of $\mathrm{BC}$ when consumed by other mammalian species, including pigs and humans, are well documented in the medical literature (Bridger and Brown, 1981; Pakkanen and Aalto, 1997; Gopal and Gill, 2000; He et al., 2001; Solomons, 2002; Uruakpa et al., 2002; Boudry et al., 2007; Struff and Sprotte, 2007). Emerging evidence indicates that $\mathrm{BC}$ is a promising nutraceutical that could prevent or mitigate various diseases in newborns and adults (Bagwe et al., 2015), in particular gastrointestinal infections. Consistent with these findings, in this study we confirmed the protective activity of $\mathrm{NHBC}$ against $\mathrm{HRoV}$, which is

Table 3. Antiviral activities ${ }^{1}$ of $\operatorname{IgG}$ from hyperimmune bovine colostrum

\begin{tabular}{|c|c|c|c|c|}
\hline Sample and virus ${ }^{2}$ (strain) & $\begin{array}{c}\mathrm{EC}_{50}(\mu \mathrm{g} / \mathrm{mL}) \\
(95 \% \mathrm{CI})\end{array}$ & $\begin{array}{c}\mathrm{EC}_{90}(\mu \mathrm{g} / \mathrm{mL}) \\
(95 \% \mathrm{CI})\end{array}$ & $\begin{array}{c}\mathrm{CC}_{50} \\
(\mu \mathrm{g} / \mathrm{mL})\end{array}$ & SI \\
\hline \multicolumn{5}{|l|}{$\operatorname{IgG}$} \\
\hline HRoV (Wa) & $1.9(1.4-2.6)$ & $19.7(10.4-37.1)$ & $>5,910$ & $>3,110$ \\
\hline HRoV (HRV408) & $1.8(0.8-3.9)$ & $12.6(2.5-63.2)$ & $>5,910$ & $>3,283$ \\
\hline HRoV (HRV248) & $0.7(0.6-0.9)$ & $8.2(4.9-13.9)$ & $>5,910$ & $>8,443$ \\
\hline BRoV (NCDV) & $6.2(5.2-7.4)$ & $30.2(19.7-49.0)$ & $>5,910$ & $>953$ \\
\hline \multicolumn{5}{|c|}{ Ammonium sulfate supernatant } \\
\hline HRoV (Wa) & $\mathrm{NA}^{3}$ & NA & $>5,910$ & NA \\
\hline HRoV (HRV408) & NA & NA & $>5,910$ & NA \\
\hline HRoV (HRV248) & NA & NA & $>5,910$ & NA \\
\hline $\mathrm{BRoV}(\mathrm{NCDV})$ & NA & NA & $>5,910$ & NA \\
\hline
\end{tabular}

${ }^{1} \mathrm{EC}_{50}=$ half-maximal effective concentration; $\mathrm{EC}_{90}=90 \%$ effective concentration; $\mathrm{CC}_{50}=$ half-maximal cytotoxic concentration; $\mathrm{SI}=$ selectivity index $\left(\mathrm{CC}_{50} / \mathrm{EC}_{50}\right)$.

${ }^{2} \mathrm{HRoV}=$ human rotavirus; $\mathrm{BRoV}=$ bovine rotavirus.

${ }^{3}$ Not assessable. 
well documented in the literature (Inagaki et al., 2010, 2013). Of note, NHBC also showed antiviral activity against several HRoV strains and, as expected, against BRoV strain NCDV, at concentrations comparable to those previously shown (Inagaki et al., 2013).

In our experimental setting, NHBC showed no significant antiviral activity against 4 viral pathogens; namely, HRhV, HCMV, HSV-1, and HSV-2. These results show that $\mathrm{BC}$ is not a broad-spectrum antiviral but rather it exerts specific antiviral activities. It is likely that this antiviral specificity and potency reflects the immunological status of the animal.

Boosting the natural concentrations of immune components in colostrum and milk by vaccinating cows offers great potential for their use as prophylactic or therapeutic products in humans. Hyperimmune BC from cows vaccinated with $\mathrm{HRoV}$ was an effective therapeutic approach to reduce the duration and severity of RoV-caused diarrhea in a double-blind controlled clinical study with infants of 6 to 24 mo of age (Mitra et al., 1995). In a second study, Davidson et al. (1989) produced HBC by introducing a vaccine containing 4 HRoV into pregnant Friesian cows. They demonstrated that this HBC administered orally mediated protection by preventing HRoV infection. Efficacy of passive immunization with HBC-derived $\mathrm{IgG}$ is documented in the literature. Hilpert et al. (1987) treated infants hospitalized with acute diarrhea with anti-rotavirus immunoglobulin concentrate without observing a significant decrease in duration of diarrhea or excretion of virus. Turner and Kelsey (1993) demonstrated a reduction in incidence and duration of diarrhea in treated infants. Sarker et al. (1998) produced HBC by immunizing pregnant cows with HRoV strains Wa, RV3, RV5, and a
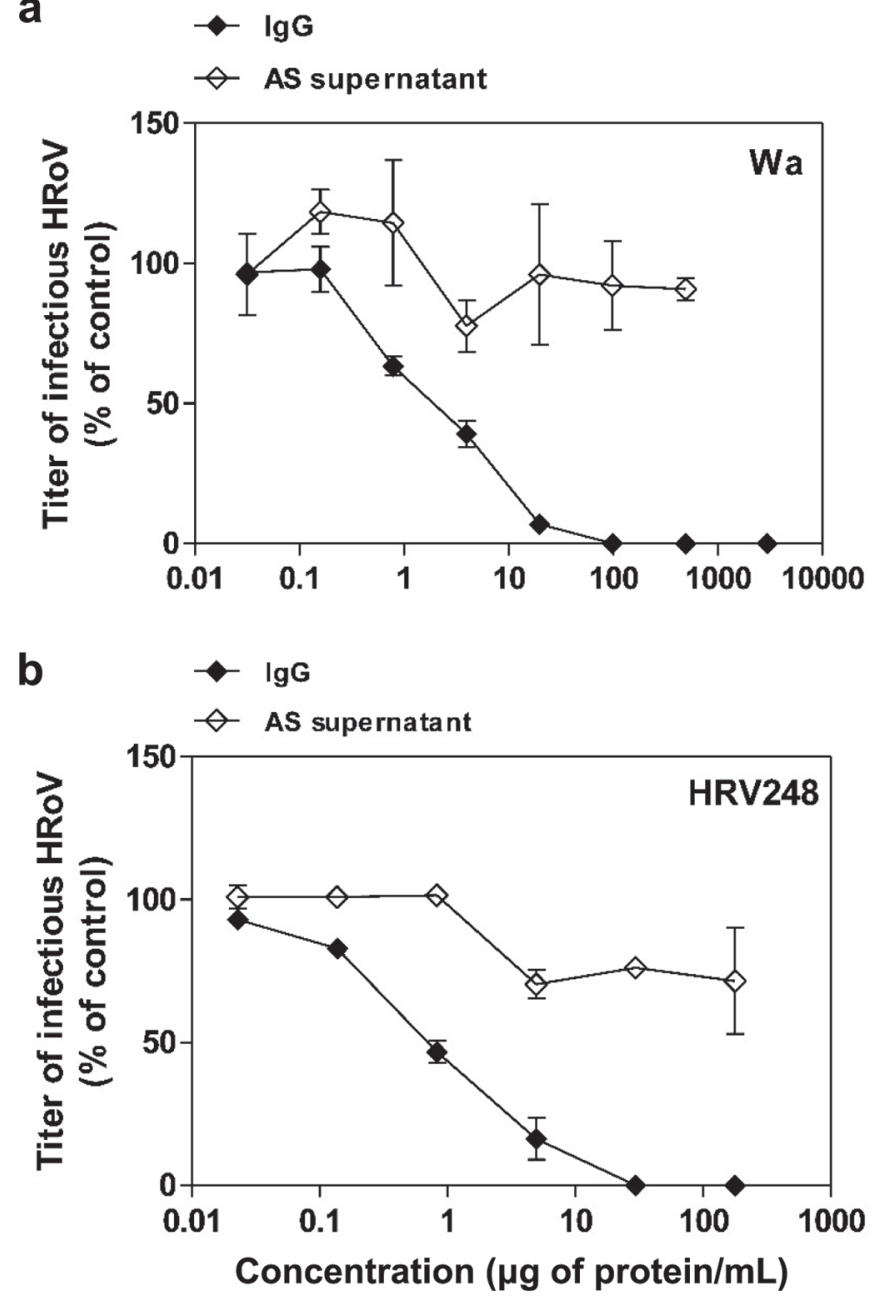

C

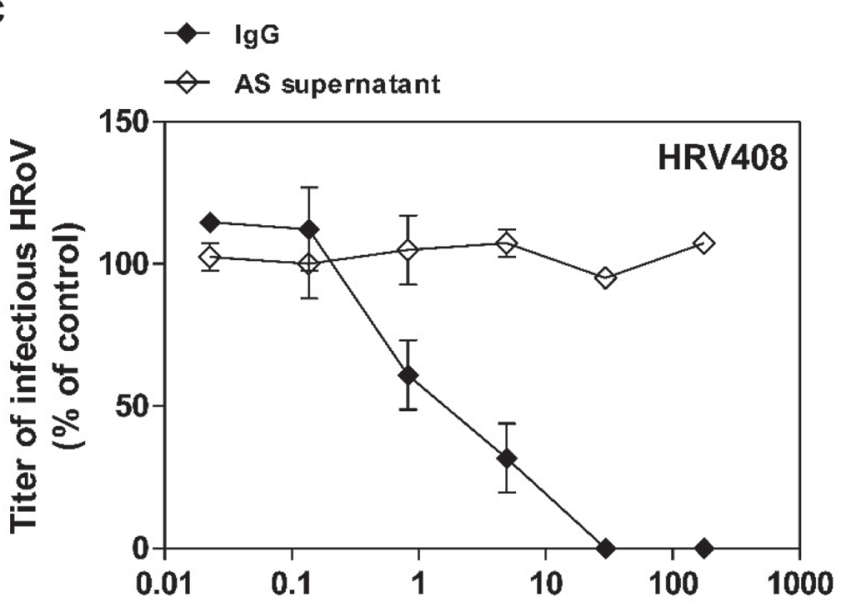

d

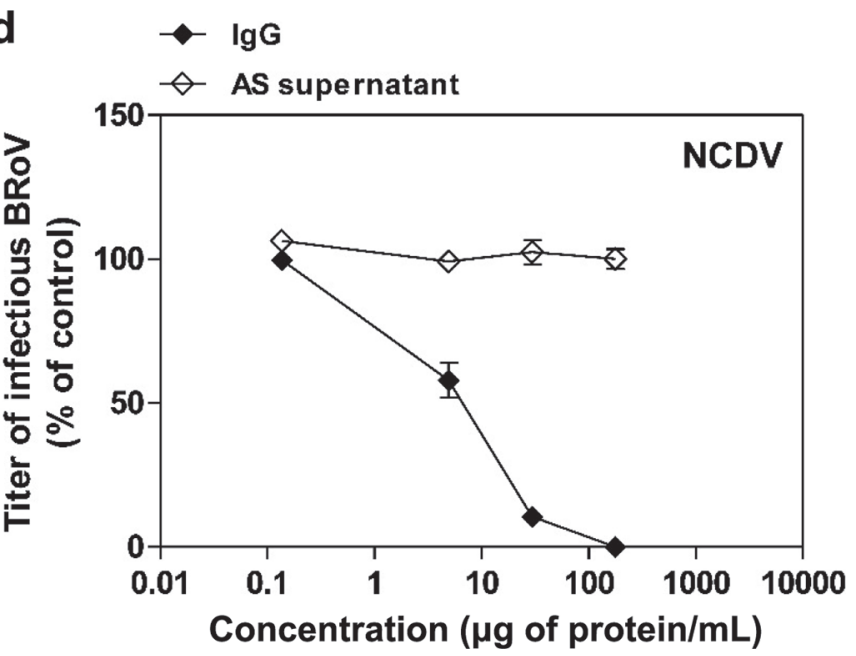

Figure 5. Antiviral activity of hyperimmune bovine colostrum (HBC)-derived IgG or ammonium sulfate (AS) supernatant against human rotavirus (HRoV) strains Wa (a), HRV248 (b), and HRV408 (c) and bovine rotavirus (BRoV) strain NCDV (d) on MA104 cells. Viral infections were detected as described in Material and Methods. The percentage infection was calculated by comparing treated and untreated wells. The results are means and SEM for duplicates. 
ST3 (representing serotypes 1 to 4, respectively). The HBC-purified IgG were then administered in a doubleblind placebo-controlled trial to children with diagnosed HRoV diarrhea. Children who received HBC-IgG had significantly less daily and total stool output and frequency and required less oral rehydration solution than did children who received placebo. However, it is difficult to generate large-scale amounts of $\mathrm{HBC}$ by immunizing cows with an unconventional $\mathrm{HRoV}$ vaccine; indeed, the yield is insufficient to cover the global requirement because over 500,000 deaths occur worldwide every year due to rotavirus-induced diarrhea (Bagwe et al., 2015). To overcome these limitations, we proposed and tested the hypothesis that HBC from cows immunized with a conventional veterinary vaccine against $\mathrm{BRoV}$ would exert a higher anti-HRoV activity than NHBC due to a high titer of cross-reactive anti-HRoV IgG. Indeed, our results confirm this hypothesis and indicate an easier and cheaper approach for the production of anti-HRoV $\mathrm{HBC}$ or IgG in cows. We demonstrated an in vitro $\mathrm{HRoV}$ inhibition efficacy (i.e., $\mathrm{EC}_{50}$ ) of $\mathrm{HBC}$ comparable to that of Inagaki and colleagues, who treated MA104 cells with skimmed and concentrated bovine late colostrum from $\mathrm{HRoV}$-immunized cows (Inagaki et al., 2010, 2013). We demonstrated that HBC and its IgG can inhibit the infectivity of $4 \mathrm{RoV}$ with 4 different a

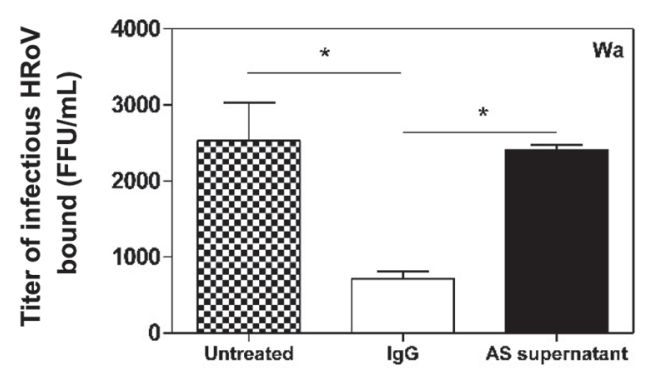

b

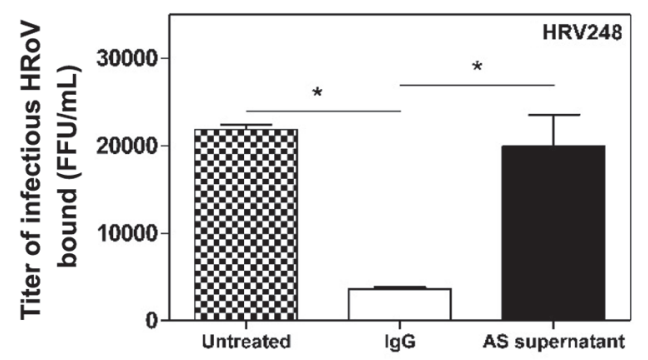

C

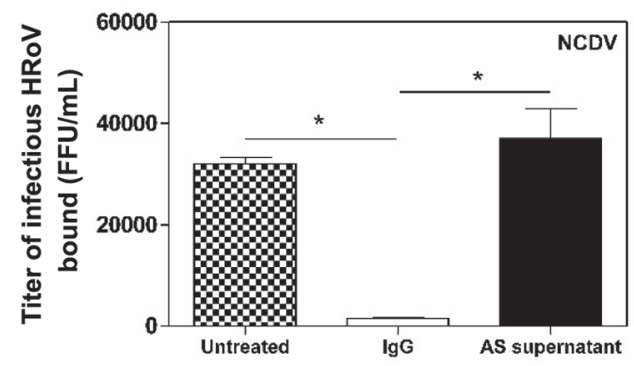

d

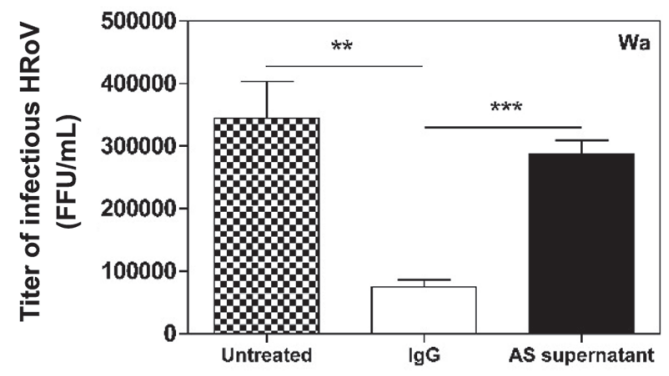

e

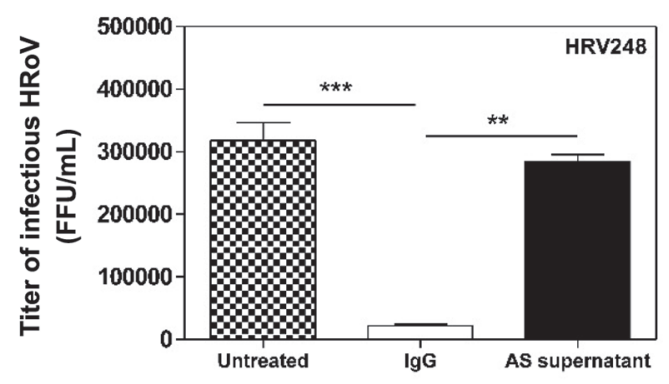

f

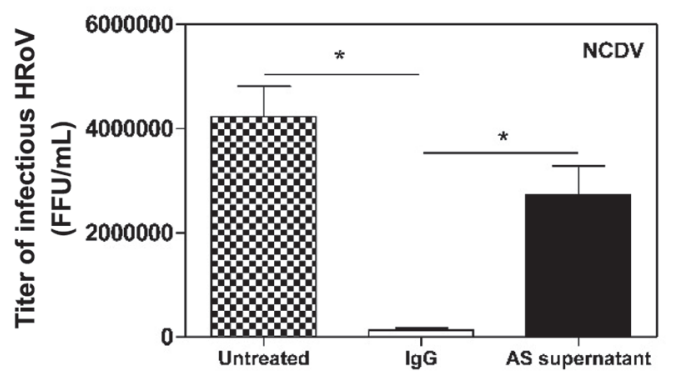

Figure 6. Mechanism of action of hyperimmune bovine colostrum (HBC)-derived IgG, untreated colostrum, or ammonium sulfate (AS) supernatant on rotavirus strains. Panels a, b, and c show the effect of HBC-derived IgG on Wa, HRV248, and NCDV, respectively, binding to the MA104 cell surface. Panels d, e, and f show the results of virus inactivation assays on infectious particles of Wa, HRV248, and NCDV, respectively. On the $\mathrm{y}$-axis, the infectious titers of $\mathrm{HRoV}$ are expressed as focus-forming units per milliliter (FFU/mL). Error bars represent the SEM of independent experiments. ${ }^{*} P<0.05,{ }^{* *} P<0.001,{ }^{* *} P<0.0001$. HRoV $=$ human rotavirus; BRoV $=$ bovine rotavirus. 
GP genotypes (Table 1), suggesting that vaccination with BRoV stimulates the production of cross-reactive neutralizing antibodies.

With a view to exploiting $\mathrm{HBC}$ as a source of antiHRoV IgG, quality assessment procedures are necessary to monitor the IgG content; nevertheless, these techniques are already available and well documented in the literature (Altomare et al., 2016a). Moreover, cows produce $\mathrm{BC}$ in large excess respective to the amount needed to feed their calves: cows produce about $33 \mathrm{~L}$ of colostrum each day in the first days after parturition, but just 4 to $6 \mathrm{~L} / \mathrm{d}$ is administered to the calf during the first $2 \mathrm{~d}$ (Devery-Pocius and Larson, 1983).

Overall, we demonstrated that the conventional $\mathrm{BRoV}$ vaccine is sufficient to boost the anti-HRoV protective efficacy of $\mathrm{BC}$. This represents a conservative, feasible, and not yield-limiting approach to produce HBC that could be exploited as a functional food to prevent and treat HRoV infections.

\section{ACKNOWLEDGMENTS}

This work was supported by a grant from "Ricerca finanziata dall'Università degli Studi di Torino" (Turin, Italy; grant number: RILO15).

\section{REFERENCES}

Altomare, A., E. Fasoli, M. Colzani, X. M. Paredes Parra, M. Ferrari, F. Cilurzo, C. Rumio, L. Cannizzaro, M. Carini, P. G. Righetti, and G. Aldini. 2016a. An in depth proteomic analysis based on ProteoMiner, affinity chromatography and nano-HPLC-MS/MS to explain the potential health benefits of bovine colostrum. J. Pharm. Biomed. Anal. 121:297-306.

Altomare, A., L. Regazzoni, X. M. P. Parra, F. Selmin, C. Rumio, M Carini, and G. Aldini. 2016b. Set-up and application of an analytical approach for the quality control of purified colostrum as food supplement. J. Chromatogr. B Analyt. Technol. Biomed. Life Sci. 1028:130-144

Babji, S., and G. Kang. 2012. Rotavirus vaccination in developing countries. Curr. Opin. Virol. 2:443-448.

Bagwe, S., L. J. Tharappel, G. Kaur, and H. S. Buttar. 2015. Bovine colostrum: An emerging nutraceutical. J. Complement. Integr. Med. 12:175-185.

Barrington, G. M., T. E. Besser, W. C. Davis, C. C. Gay, J. J. Reeves, and T. B. McFadden. 1997. Expression of immunoglobulin G1 receptors by bovine mammary epithelial cells and mammary leukocytes. J. Dairy Sci. 80:86-93.

Benson, K. F., S. G. Carter, K. M. Patterson, D. Patel, and G. S. Jensen. 2012. A novel extract from bovine colostrum whey supports anti-bacterial and anti-viral innate immune functions in vitro and in vivo: I. Enhanced immune activity in vitro translates to improved microbial clearance in animal infection models. Prev. Med. 54:S116-S123.

Binder, H. J., I. Brown, B. S. Ramakrishna, and G. P. Young. 2014 Oral rehydration therapy in the second decade of the twenty-first century. Curr. Gastroenterol. Rep. 16:376-384

Bojsen, A., J. Buesa, R. Montava, A. S. Kvistgaard, M. B. Kongsbak, T. E. Petersen, C. W. Heegaard, and J. T. Rasmussen. 2007. Inhibitory activities of bovine macromolecular whey proteins on rotavirus infections in vitro and in vivo. J. Dairy Sci. 90:66-74.
Boudry, C., A. Buldgen, D. Portetelle, A. Collard, A. Thewis, and J. P. Dehoux. 2007. Effects of oral supplementation with bovine colostrum on the immune system of weaned piglets. Res. Vet. Sci. 83:91-101.

Bridger, J. C., and J. F. Brown. 1981. Development of immunity to porcine rotavirus in piglets protected from disease by bovine colostrum. Infect. Immun. 31:906-910.

Bush, L. J., and T. E. Staley. 1980. Absorption of colostral immunoglobulins in newborn calves. J. Dairy Sci. 63:672-680.

Byakwaga, H., M. Kelly, D. F. Purcell, M. A. French, J. Amin, S. R. Lewin, H. Haskelberg, A. D. Kelleher, R. Garsia, M. A. Boyd, D. A. Cooper, and S. Emery. 2011. CORAL Study Group. Intensification of antiretroviral therapy with raltegravir or addition of hyperimmune bovine colostrum in HIV-infected patients with suboptimal CD4+ T-cell response: A randomized controlled trial. J. Infect. Dis. 204:1532-1540.

Cagno, V., A. Civra, D. Rossin, S. Calfapietra, C. Caccia, V. Leoni, N. Dorma, F. Biasi, G. Poli, and D. Lembo. 2017. Inhibition of herpes simplex-1 virus replication by 25-hydroxycholesterol and 27 hydroxycholesterol. Redox Biol. 12:522-527.

Civra, A., V. Cagno, M. Donalisio, F. Biasi, G. Leonarduzzi, G. Poli, and D. Lembo. 2014. Inhibition of pathogenic non-enveloped viruses by 25-hydroxycholesterol and 27-hydroxycholesterol. Sci. Rep. 4:7487.

Civra, A., M. G. Giuffrida, M. Donalisio, L. Napolitano, Y. Takada, B. S. Coulson, A. Conti, and D. Lembo. 2015. Identification of equine lactadherin-derived peptides that inhibit rotavirus infection via integrin receptor competition. J. Biol. Chem. 290:12403-12414.

Cohen, S. M. 2006. Jaundice in the full-term newborn. Pediatr. Nurs $32: 202-208$.

Das, J. K., R. A. Salam, and Z. A. Bhutta. 2014. Global burden of childhood diarrhea and interventions. Curr. Opin. Infect. Dis. $27: 451-458$.

Davidson, G. P., P. B. Whyte, E. Daniels, K. Franklin, H. Nunan, P. I. McCloud, A. G. Moore, and D. J. Moore. 1989. Passive immunisation of children with bovine colostrum containing antibodies to human rotavirus. Lancet 2:709-712.

Devery-Pocius, J. E., and B. L. Larson. 1983. Age and previous lactations as factors in the amount of bovine colostral immunoglobulins. J. Dairy Sci. 66:221-226.

Ebina, T., M. Ohta, Y. Kanamaru, Y. Yamamoto-Osumi, and K Baba. 1992. Passive immunizations of suckling mice and infants with bovine colostrum containing antibodies to human rotavirus. J. Med. Virol. 38:117-123.

El-Fakharany, E. M., V. N. Uversky, and E. M. Redwan. 2017. Comparative analysis of the antiviral activity of camel, bovine, and human lactoperoxidases against Herpes Simplex virus type 1. Appl. Biochem. Biotechnol. 182:294-310.

Gaspar, H. B., L. Hammarström, N. Mahlaoui, M. Borte, and S. Borte. 2014. The case for mandatory newborn screening for severe combined immunodeficiency (SCID). J. Clin. Immunol. 34:393-397.

Glass, R. I., U. Parashar, M. Patel, J. Gentsch, and B. Jiang. 2014 Rotavirus vaccines: Successes and challenges. J. Infect. 68:S9-18.

Gopal, P. K., and H. S. Gill. 2000. Oligosaccharides and glycoconjugates in bovine milk and colostrum. Br. J. Nutr. 84:S69-S74.

Hammarström, L., and C. K. Weiner. 2008. Targeted antibodies in dairy-based products. Adv. Exp. Med. Biol. 606:321-343.

He, F., E. Tuomola, H. Arvilommi, and S. Salminen. 2001. Modulation of human humoral immune response through orally administered bovine colostrum. FEMS Immunol. Med. Microbiol. 31:93-96.

Hilpert, H., H. Brüssow, C. Mietens, J. Sidoti, L. Lerner, and H. Werchau. 1987. Use of bovine milk concentrate containing antibody to rotavirus to treat rotavirus gastroenteritis in infants. J. Infect. Dis. 156:158-166

Inagaki, M., H. Muranishi, K. Yamada, K. Kakehi, K. Uchida, T. Suzuki, T. Yabe, T. Nakagomi, O. Nakagomi, and Y. Kanamaru. 2014. Bovine $\kappa$-casein inhibits human rotavirus (HRV) infection via direct binding of glycans to HRV. J. Dairy Sci. 97:2653-2661.

Inagaki, M., M. Yamamoto, Xijier, Cairangzhuoma, K. Uchida, H. Yamaguchi, M. Kawasaki, K. Yamashita, T. Yabe, and Y. Kanamaru. 2010. In vitro and in vivo evaluation of the efficacy of bo- 
vine colostrum against human rotavirus infection. Biosci. Biotechnol. Biochem. 74:680-682.

Inagaki, M., M. Yamamoto, Cairangzhuoma, Xijier, T. Yabe, K. Uchida, M. Kawasaki, T. Nakagomi, O. Nakagomi, N. Minamoto, and Y. Kanamaru. 2013. Multiple-dose therapy with bovine colostrum confers significant protection against diarrhea in a mouse model of human rotavirus-induced gastrointestinal disease. J. Dairy Sci. 96:806-814.

Kelly, G. S. 2003. Bovine colostra: A review of clinical uses. Altern. Med. Rev. 8:378-394.

Korhonen, H., P. Marnila, and H. S. Gill. 2000. Bovine milk antibodies for health. Br. J. Nutr. 84:S135-S146.

Kramski, M., R. J. Center, A. K. Wheatley, J. C. Jacobson, M. R. Alexander, G. Rawlin, and D. F. Purcell. 2012a. Hyperimmune bovine colostrum as a low-cost, large-scale source of antibodies with broad neutralizing activity for HIV-1 envelope with potential use in microbicides. Antimicrob. Agents Chemother. 56:4310-4319.

Kramski, M., G. F. Lichtfuss, M. Navis, G. Isitman, L. Wren, G. Rawlin, R. J. Center, A. Jaworowski, S. J. Kent, and D. F. Purcell. 2012b. Anti-HIV-1 antibody-dependent cellular cytotoxicity mediated by hyperimmune bovine colostrum IgG. Eur. J. Immunol. 42:2771-2781.

Larson, B. L., H. L. Heary, and J. E. Devery. 1980. Immunoglobulin production and transport by the mammary gland. J. Dairy Sci. 63:665-671.

Macy, I. G. 1949. Composition of human colostrum and milk. Am. J. Dis. Child. 78:589-603.

Majumdar, A. S., and A. C. Ghose. 1982. Protective properties of anticholera antibodies in human colostrum. Infect. Immun. 36:962-965.

Marcotte, H., and L. Hammarström. 2016. Immunodeficiencies: Significance for gastrointestinal disease. Pages 47-72 in Viral Gastroenteritis. Molecular Epidemiology and Pathogenesis. L. Svensson, U. Desselberger, H. B. Greenberg, and M. K. Estes, ed. Academic Press, London, UK.

Mehra, R. 2006. Milk Ig for health promotion. Int. Dairy J. 16:12621271.

Mitra, A. K., D. Mahalanabis, H. Ashraf, L. Unicomb, R. Eeckles, and S. Tzipori. 1995. Hyperimmune cow colostrum reduces diarrhoea due to rotavirus: A double-blind, controlled clinical trial. Acta Paediatr. 84:996-1001.

Moore, M., J. W. Tyler, M. Chigerwe, M. E Dawes, and J. R. Middleton. 2005. Effect of delayed colostrum collection on colostral IgG concentration in dairy cows. J. Am. Vet. Med. Assoc. 226:13751377.

Morris, J. A., C. Wray, and W. J. Sojka. 1980. Passive protection of lambs against enteropathogenic Escherichia coli: Role of antibodies in serum and colostra. J. Med. Microbiol. 13:265-271.

Ng, W. C., V. Wong, B. Muller, G. Rawlin, and L. E. Brown. 2010. Prevention and treatment of influenza with hyperimmune bovine colostrum antibody. PLoS One 5:e13622.

Ogra, S. S., and P. L. Ogra. 1978. Immunological aspects of human colostrum and milk. J. Pediatr. 92:550-555.

Pakkanen, R., and J. Aalto. 1997. Growth factors and antimicrobial factors in bovine colostrum. Int. Dairy J. 7:285-297.

Parrón, J. A., D. Ripollés, A. C. Sánchez, M. D. Pérez, M. Calvo, S. López, C. F. Arias, and L. Sánchezm. 2018. Antirotaviral activity of bovine milk components: Extending the list of inhibitory proteins and seeking a better understanding of their neutralization mechanism. J. Funct. Foods 44:103-111.
Payne, D. C., J. A. Boom, M. A. Staat, K. M. Edwards, P. G. Szilagyi, E. J. Klein, and U. D. Parashar. 2013. Effectiveness of pentavalent and monovalent rotavirus vaccines in concurrent use among US children $<5$ years of age, 2009-2011. Clin. Infect. Dis. 57:13-20.

Playford, R. J., C. E. Macdonald, and W. S. Johnson. 2000. Colostrum and milk-derived peptide growth factors for the treatment of gastrointestinal disorders. Am. J. Clin. Nutr. 72:5-14.

Rahman, S., K. Higo-Moriguchi, K. W. Htun, K. Taniguchi, F. C. Icatlo Jr., T. Tsuji, Y. Kodama, S. V. Nguyen, K. Umeda, H. N. Oo, Y. Y. Myint, T. Htut, S. S. Myint, K. Thura, H. M. Thu, N. N. Dwi Fatmawati, and K. Oguma. 2012. Randomized placebocontrolled clinical trial of immunoglobulin $\mathrm{Y}$ as adjunct to standard supportive therapy for rotavirus-associated diarrhea among pediatric patients. Vaccine 30:4661-4669.

Rainard, P., and C. Riollet. 2006. Innate immunity of the bovine mammary gland. Vet. Res. 37:369-400.

Sacerdote, P., F. Mussano, S. Franchi, A. E. Panerai, G. Bussolati, S. Carossa, A. Bartorelli, and B. Bussolati. 2013. Biological components in a standardized derivative of bovine colostrum. J. Dairy Sci. 96:1745-1754.

Sarker, S. A., T. H. Casswall, D. Mahalanabis, N. H. Alam, M. J. Albert, H. Brussow, G. J. Fuchs, and L. Hammerstrom. 1998. Successful treatment of rotavirus diarrhea in children with immunoglobulin from immunized bovine colostrum. Pediatr. Infect. Dis. J. 17:1149-1154.

Smolenski, G., S. Haines, F. Y. Kwan, J. Bond, V. Farr, S. R. Davis, K. Stelwagen, and T. T. Wheeler. 2007. Characterisation of host defence proteins in milk using a proteomic approach. J. Proteome Res. 6:207-215.

Solomons, N. W. 2002. Modulation of the immune system and the response against pathogens with bovine colostrum concentrates. Eur. J. Clin. Nutr. 56:S24-S28.

Stelwagen, K., E. Carpenter, B. Haigh, A. Hodgkinson, and T. T. Wheeler. 2009. Immune components of bovine colostrum and milk. J. Anim. Sci. 87:3-9.

Stephan, W., H. Dichtelmuller, and R. Lissner. 1990. Antibodies from colostrum in oral immunotherapy. J. Clin. Chem. Clin. Biochem. 28:19-23

Struff, W. G., and G. Sprotte. 2007. Bovine colostrum as a biologic in clinical medicine: A review. Part I: Biotechnological standards, pharmacodynamic and pharmacokinetic characteristics and principles of treatment. Int. J. Clin. Pharmacol. Ther. 45:193-202.

Struff, W. G., and G. Sprotte. 2008. Bovine colostrum as a biologic in clinical medicine: A review-Part II: Clinical studies. Int. J. Clin. Pharmacol. Ther. 46:211-225.

Tate, J. E., A. H. Burton, C. Boschi-Pinto, and U. D. Parashar. 2016 Global, regional, and national estimates of rotavirus mortality in children $<5$ years of age, 2000-2013. Clin. Infect. Dis. 62:S96-105.

Thapa, B. R. 2005. Health factors in colostrum. Indian J. Pediatr. $72: 579-581$

Tokuyama, H., Y. Tokuyama, and S. Migita. 1990. Isolation of two new proteins from bovine colostrum which stimulate epidermal growth factor-dependent colony formation of NRK-49f cells. Growth Factors 3:105-114.

Turner, R. B., and D. K. Kelsey. 1993. Passive immunization for prevention of rotavirus illness in healthy infants. Pediatr. Infect. Dis. J. $12: 718-722$

Uruakpa, F. O., M. A. H. Ismond, and E. N. T. Akobundu. 2002. Colostrum and its benefits: A review. Nutr. Res. 22:755-767. 